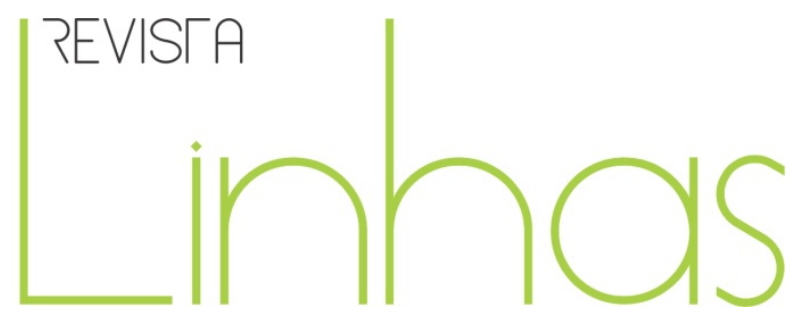

\title{
Francisco Pompêo do Amaral: sujeito social e seus objetos de ensino em prol da alimentação e nutrição no Brasil (1938 a 1941)
}

\section{Resumo}

Este artigo se propõe mostrar o médico Francisco Pompêo do Amaral (1907-1990) como pioneiro na criação dos cursos no campo da alimentação e nutrição no Brasil. O primeiro, que promoveu em São Paulo e abriu com a aula inaugural em 17 de maio de 1939, revelou os docentes e discentes que contribuíram para a implantação do curso de auxiliares em alimentação na Superintendência do Ensino Profissional do estado de São Paulo. Este médico publicou muitos livros e artigos em revistas científicas, mas quase não existem registros sobre essa primazia. Para relacionar o "estilo de pensamento científico" de Francisco Pompêo do Amaral com o de seus contemporâneos, Geraldo de Paula Souza (1889-1951) e Josué de Castro (1908-1973), também pioneiros na criação de cursos no campo da alimentação e nutrição no País, empregaram-se nesta pesquisa a categoria de investigação da cultura escolar e a de práticas escolares e pedagógicas, identificando os protagonistas e os currículos dos primeiros cursos no campo da alimentação e nutrição no Brasil no período de 1939 a 1941, buscando compreender o pensamento coletivo de uma época. Francisco Pompêo do Amaral realizou estudos e pesquisas na década de 1940, publicados na Revista Brasileira Agrícola, sobre a alimentação do povo brasileiro, incluindo em suas obras as práticas pedagógicas e escolares desenvolvidas com estudantes e sua equipe de dietistas. Tais estudos e pesquisas se encontram em centros de memória escolares e institucionais. Estas práticas culminaram com a publicação do livro “Política Alimentar”, pela Editora Brasiliense, em 1945.

Palavras-chave: Educação Profissional; Alimentação e nutrição; História da educação; Cultura escolar; Centros de memória.
Maria Lucia Mendes de Carvalho

Doutora em Engenharia Agrícola pela Universidade Estadual de

Campinas - UNICAMP

maria.carvalho@centropaulasouz a.sp.gov.br

\section{Maria Ângela Fagnani Doutora em Educação pela Universidade Estadual de Campinas - UNICAMP angela@feagri.unicamp.br}

\begin{abstract}
Para citar este artigo:
CARVALHO, Maria Lucia Mendes de; FAGNANI, Maria Ângela. Francisco Pompêo do Amaral: sujeito social e seus objetos de ensino em prol da alimentação e nutrição no Brasil (1938 a 1941). Revista Linhas, Florianópolis, v. 15, n. 28, p. 100-126, jan./jun. 2014.
\end{abstract}

DOI: $10.5965 / 1984723815282014100$

http://dx.doi.org/10.5965/1984723815282014100 


\title{
Francisco Pompêo do Amaral: social subject and its teaching objects in favor of Food and Nutrition in Brazil (1938 - 1941)
}

\begin{abstract}
This article drives to elucidate the primacy of medical Francisco Pompêo do Amaral (1907-1990) in the creation of the first course in the field of food and nutrition in Brazil, which took place in São Paulo, unraveling teachers and students who contributed to the ongoing deployment of "Food Assistants", which occurred in the Superintendency of Professional Education of the State of São Paulo, with the inaugural class on 17th May 1939. This doctor has published many books and articles in scientific journals, but there are hardly any records about this primacy. To relate the "style of scientific thinking" of Francisco Pompêo do Amaral with his contemporaries Geraldo de Paula Souza (1889-1951) and Josué de Castro (1908-1973). Who were also pioneers in creating courses in the field of food and nutrition in the country, was employed in this study the research categories of school culture and school practices and teaching, identifying the protagonists and the curricula of the first courses in the field of food and nutrition in Brazil, in the period 1939-1941, and seeking understand the collective thought of an epoch. Francisco Pompêo do Amaral conducted studies and researches in 1940s, which were published in the "Revista Brasileira Agrícola" about the nourishment of the Brazilian people, including in this work in the teaching and school practices developed with students and his team of dietitians, located in centers school and institutional memory. These practices culminated in the publication of the book "Food Politics" by Editora Brasiliense in 1945.
\end{abstract}

Keywords: Professional education; Food and nutrition; History of education; School culture; Memory centers. 
Este artigo contribui com a história da educação no campo da alimentação e nutrição em saúde coletiva, devido ao surgimento, há 74 anos, do curso "Auxiliares em Alimentação", o primeiro no campo da alimentação e nutrição no País, criado por Francisco Pompêo do Amaral. A aula inaugural desse curso aconteceu em 17 de maio de 1939, na primeira Superintendência do Ensino Profissional do estado de São Paulo. O documento que comprova tal primazia foi localizado em 2001, no acervo do Centro de Memória da Escola Técnica Estadual Carlos de Campos.

A descoberta aconteceu durante a pesquisa iconográfica e documental para a elaboração do “Álbum Fotográfico - Uma História em Imagens - das Escolas Profissionais Públicas do Estado de São Paulo" (MORAES e ALVES, 2002), como um dos produtos do projeto “Historiografia das Escolas Técnicas Estaduais mais Antigas do Estado de São Paulo", proposto pelo Centro de Memória da Educação da Faculdade de Educação da Universidade de São Paulo, sob a coordenação geral da dra. Carmen Sylvia Vidigal de Moraes, em parceria com o Centro Paula Souza, e coordenado, nessa instituição, pela professora Julia Falivene Alves, da Unidade de Ensino Médio e Técnico, envolvendo oito escolas técnicas. Esse projeto foi iniciado em 1998. Teve duração de quatro anos, com financiamento da Fundação de Apoio à Pesquisa do Estado de São Paulo (Fapesp) (MORAES; ZAIA; VENDRAMETO, 2005, p.118). O documento da aula inaugural do curso de auxiliares em alimentação suscitou uma questão a ser investigada: "Quem criou o primeiro curso no campo da alimentação e nutrição no Brasil?".

Francisco Pompêo do Amaral (1907-1990) foi médico, jornalista, professor, escritor e cientista, exercendo todos esses papéis durante a sua vida em prol da alimentação e nutrição no País. Formou-se médico endocrinologista pela Faculdade de Medicina de São Paulo, em 1933. Mas, ainda estudante, começou a atuar como jornalista. Como médico, iniciou a sua carreira no Departamento de Educação Física da Secretaria da Educação e Saúde Pública do Estado de São Paulo, atuando na Cruzada Pró-Infância. 
Em São Paulo, a Escola Superior de Educação Física foi fundada para formar “Instructores de Gymnástica", sendo o primeiro curso, e o que deu origem à Escola de Educação Física da Universidade de São Paulo, por iniciativa do dr. Fernando de Azevedo, diretor de educação no estado de São Paulo. Massucato e Barbanti (1999) relatam que a aula inaugural desse curso aconteceu em 4 de agosto de 1934 para promover atividades físicas para crianças de sete a oito anos de idade, em uma sala do Parque Infantil no Parque Dom Pedro II, no período de agosto de 1934 a abril de 1936, empregando um método francês e as disciplinas: "Anatomia Humana, Physiologia Humana, Hygiene, Noções de Psychologia Educativa, Educação Physica, Noções de Orthopedia e História da Educação Physica”. Entre os docentes, além de Pompêo do Amaral, estavam:

Dr. Arne Ragnar Eng., Dr. Américo Netto do Rego Cavalcanti, Dr. Francisco Pompeu do Amaral, Dr. João Alves Meira, Dr. Miguel Leuzzi, Prof. Jarbas Salles Figueiredo, Prof. Antonio de Castro Carvalho, Prof. José Villela Bastos, Prof. IdylioAlcantara de Oliveira Abbade, Prof. Alfredo Giorgetti e Prof. AlvaroCardoso. (MASSUCATO; BARBANTI,1999)

De 1934 até fins de 1938, Francisco Pompêo do Amaral foi professor nos cursos normais e nos extraordinários da Escola Superior de Educação Física, ministrando a cadeira de "Mecânica Animal e Cinesielogia"; durante dois anos, a de "Fisioterapia". Durante o período em que lecionou nessa escola, pronunciou diversas conferências, duas das quais foram incluídas no livro "Educação Física - Conferências", publicado em 1936 (POMPÊO DO AMARAL, 1963).

Francisco Pompêo do Amaral, integrado ao Departamento de Educação Física da Secretaria da Educação e Saúde Pública do Estado de São Paulo, foi novamente comissionado junto à Cruzada Pró-Infância; entre 1937 e 1939, ministrou aulas de dietética, contribuindo com a divulgação de noções de alimentação racional.

Em janeiro de 1934, começou a publicar matérias jornalísticas nas Folhas “da Manhã”, “da Tarde”, “da Noite” e "de São Paulo”, com a finalidade de popularizar os conhecimentos de higiene junto à população e promover intensa campanha em prol da racionalização da alimentação popular, o que possibilitou divulgar em outros jornais nacionais suas matérias jornalísticas (POMPÊO DO AMARAL, 1963). Entre 30 de novembro de 1937 e 14 maio de 1939, foi responsável por “Lições Populares sobre Alimentação" na 
Folha da Manhã; nesse jornal, pode ter conhecido a professora Celina de Moraes Passos, que escrevia “Algumas receitas interessantes" para o mesmo periódico.

Celina de Moraes Passos ingressou no curso da Escola Normal Feminista de Artes e Ofícios Carlos de Campos, no Brás, em São Paulo, em 1932. Essa escola oferecia, desde 1931, o curso normal para Formação de Mestras em Educação Doméstica, criado por seu diretor, Horácio Augusto da Silveira. Logo que se formou, a normalista prestou concurso nessa escola para o cargo de segunda mestra em Economia Doméstica (UNIVERSIDADE, 2012). Freitas (1954, p.72) relata que o Decreto Estadual $n^{\circ} 5.885$, de 21 de abril de 1933, artigo 16, transformou a cadeira de "Economia Doméstica" do Instituto Profissional Feminino, antiga Escola Normal Feminista de Artes e Ofícios Carlos de Campos, da capital, e nas escolas profissionais secundárias mistas em cadeira de "Economia Doméstica e Química”, continuando no cargo as mesmas docentes.

Em 1936, Celina de Moraes Passos fez estágio de prática de Química Bromatológica na Inspetoria do Policiamento da Alimentação Pública do Serviço Sanitário do Estado de São Paulo. No período de 1937 a 1938, participou do curso especial teóricoprático de Dietética, no Departamento de Fisiologia da Faculdade de Medicina da Universidade de São Paulo. Em 1938, publicou o livro “Noções sobre Química Alimentar”, pela Companhia Editora Nacional. No prefácio, Francisco Pompêo do Amaral elogia a atuação de Celina de Moraes Passos por seu esforço em prol da racionalização da alimentação popular, concluindo que "a ilustre direção das Escolas Profissionais, a que presta seu auxílio, saiba tirar dela e de outras os melhores proveitos, em benefício da racionalização da alimentação do paulista, são os votos que entusiasticamente formulamos" (PASSOS, 1938, p.15-16).

Nas instituições escolares, para se estudar e pesquisar as memórias e a história da educação em seus arquivos permanentes, repletos de prontuários de estudantes, os planos de ensino e as legislações, muitas vezes há necessidade de novos espaços que levem à criação de centros de memória nas escolas. Esses centros, com documentos textuais e iconográficos de arquivos escolares e com objetos museológicos empregados em práticas escolares e pedagógicas no passado, integrantes do patrimônio histórico, educativo e tecnológico, passam a constituir lugares de memórias. Vinão (2011, p.34) 
considera que o patrimônio é sempre um processo inacabado de construção e reconstrução; por isso ocorrem "conflitos e lutas para apoderar-se da memória social de um grupo determinado, afetando em cada momento o que se considera digno de ser patrimoniável, conservado e convertido em lugar de memória”.

Para realizar esta pesquisa, empregaram-se documentos textuais e iconográficos localizados nos acervos de centros de memória de escolas da educação profissional no estado de São Paulo; na Faculdade de Educação da USP; na Faculdade de Saúde Pública da USP e da Unicamp; no Banco de Dados da Folha de São Paulo; nos acervos pessoais de Francisco Pompêo do Amaral e de Debble Smaíra Pasotti, também em São Paulo; nos acervos da Academia Nacional de Medicina; no Arquivo Central da Universidade Federal do Estado do Rio de Janeiro (UNIRIO); na Biblioteca Nacional e no Centro de Pesquisa e Documentação da Fundação Getúlio Vargas (FGV), no Rio de Janeiro e no Centro de Estudos e Pesquisas Josué de Castro, em Recife. Para Rosa Fátima de Souza (2013), “os estudos sobre cultura escolar na busca incansável por vestígios das práticas foram significativamente importantes no direcionamento dos pesquisadores para a consulta aos arquivos escolares".

No acervo do Centro de Memória da Escola Técnica Estadual Carlos de Campos, em São Paulo, encontra-se o "Livro de Recortes de Jornais”, organizado durante 20 anos pela diretora Laia Pereira Bueno, o qual contribuiu muito para desvendar a origem e os protagonistas do curso de auxiliares em alimentação na Superintendência do Ensino Profissional no estado de São Paulo.

Para relacionar o "estilo de pensamento científico" de Francisco Pompêo do Amaral com o de seus contemporâneos, Geraldo de Paula Souza (1889-1951) e Josué de Castro (1908-1973), também pioneiros na criação de cursos no campo da alimentação e nutrição no País, empregaram-se, nesta pesquisa, categorias de investigação da cultura escolar (JULIA, 2001; VIÑAO FRAGO, 2004, 2011) e de práticas escolares e pedagógicas (GVIRTZ, 2005), identificando a gênese do primeiro curso no campo da alimentação e nutrição no Brasil, a aula inaugural do curso de Auxiliares em Alimentação em São Paulo, os currículos e protagonistas desses primeiros cursos e as práticas escolares e 
pedagógicas no ensino profissional no período de 1939 a 1941, buscando compreender o pensamento coletivo de uma época.

\section{A gênese do primeiro curso no campo da alimentação e nutrição no Brasil}

Em janeiro de 1939, Francisco Pompêo do Amaral ingressou, como médico-chefe, na Superintendência do Ensino Profissional. Um documento por ele elaborado para se candidatar a uma vaga de membro correspondente nacional na Academia Nacional de Medicina, no Rio de Janeiro, denominado "Trabalhos e títulos do Doutor Francisco Pompêo do Amaral", de 4 de agosto de 1963, e na qual foi empossado em 1969, mostra como aconteceu o seu ingresso na educação profissional pública do estado de São Paulo:

Convidado pelo Secretário da Educação e da Saúde Pública assumiu, a 2 de janeiro de 1939, o cargo de médico-chefe da Superintendência do Ensino Profissional. Cuidou, então, de organizar imediatamente os cursos de formação de técnicas em dietética (antes, Curso de Formação de Auxiliares em Alimentação, e, hoje, Curso de Formação de Dietistas), de acordo com as idéias que tinha exposto no artigo "UMA CLASSE DE PROFSSIONAIS DE QUE A NAÇÃO CARECE", publicada pela "Folha da Manhã", de São Paulo, em 15-VII-1938, e pela "Folha de Minas", de Belo Horizonte, em 5-Xl-1938 - bem como no prefácio, de sua autoria, do livro "Noções sobre Química Alimentar", de lavra da Profa. Celina de Morais Passos, editado pela Cia. Editôra Nacional, em 1938 (pags. 7 a 16) e ainda cursos de divulgação teórico-práticos de conhecimentos de dietética e arte culinária (Cursos de Dietética para Donas de Casa). Inaugurados solenemente em 17 de maio de 1939, com aula que esteve a seu cargo, foram tais cursos, no gênero, os primeiros instalados no país e constituíram poderosa sugestão para a imediata criação de outros. (POMPÊO DO AMARAL, 1963)

No ano que ingressou na Superintendência do Ensino Profissional do Estado de São Paulo, existiam, de acordo com Laurindo, as seguintes escolas profissionais, criadas em diferentes épocas:

Instituto Profissional Masculino, na capital, com anexos da Escola Técnica Profissional e Cursos de Ferroviários (1911); Instituto Profissional Feminino, na capital (1911); Escola Profissional Secundária Masculina João Belarmino, de Amparo (1913); Escola Profissional Secundária Masculina, de Rio Claro, com anexo o Curso de Ferroviários, em Rio Claro (1920); 
Escola Profissional Secundária Mista Dr. Julio Cardoso, de Franca (1924); Escola Secundária Mixta de Ribeirão Preto (1927); Escola Profissional Secundária Mista Bento Quirino, de Campinas, com anexos os Cursos de Ferroviários (1927); Escola Profissional Secundária Mista Cel. Fernando Prestes, de Sorocaba, com anexos Cursos Ferroviários (1929); Escola Profissional Secundária Mista Cel. Francisco Garcia, de Mococa (1931); Escola Profissional Secundária Mista, de São Carlos (1933); Instituto D. Escolástica Rosa (Escola Profissional Secundária Mista, mantendo internato para os alunos, com anexo um Curso de Formação e Seleção de Operários para Serviços Marítimos e Portuários (1934); Escola Profissional Secundária Feminina do Seminário de Educandas, na capital, com anexo um internato para as alunas (1935); Escola Profissional Secundária Mista de Botucatu (1937); Escola Profissional Primária Mista Dr. Sales Gomes, de Tatuí (1938); Escola Profissional Secundária Mista de Lins (1939); Escola Profissional Agrícola Industrial de Pinhal (mista) (1935); Escola Profissional Agrícola Industrial Cônego José Bento, de Jacareí (masculina) (1938). (LAURINDO, 1962, v. 1, p. 174-5)

Nessa superintendência aconteceu, entre 31 de março e 2 de abril, de 1939, o "Congresso dos Directores das Escolas Profissionaes", com a participação de 150 diretores e professores de Economia Doméstica (Figura 1), tendo como pauta: a classificação objetiva dos trabalhos dos cursos vocacionais; o ensino de "electromecânica", as artes e ofícios femininos, e aula prática de dietética. Oscar Lindholm de Oliveira, inspetor geral na superintendência, participou da abertura do evento, dando orientações para que os cursos vocacionais atingissem a sua importante finalidade de formar artífices; recomendou aos diretores orientar os aprendizes na escolha do ofício relacionado com as suas aptidões. Para isso, foram "organizadas fichas de controle de evolução do alumno vocacional, nos trabalhos da seriação artífice”. 
Figura 1 - Matéria jornalística, de 3 de abril de 1939, mostra a equipe de professores do primeiro curso de auxiliares em alimentação, com o médico Francisco Pompêo do Amaral; embaixo, a professora Zenith Freire ministrando aula prática de dietética durante o congresso realizado na Superintendência do Ensino Profissional do Estado de São Paulo.

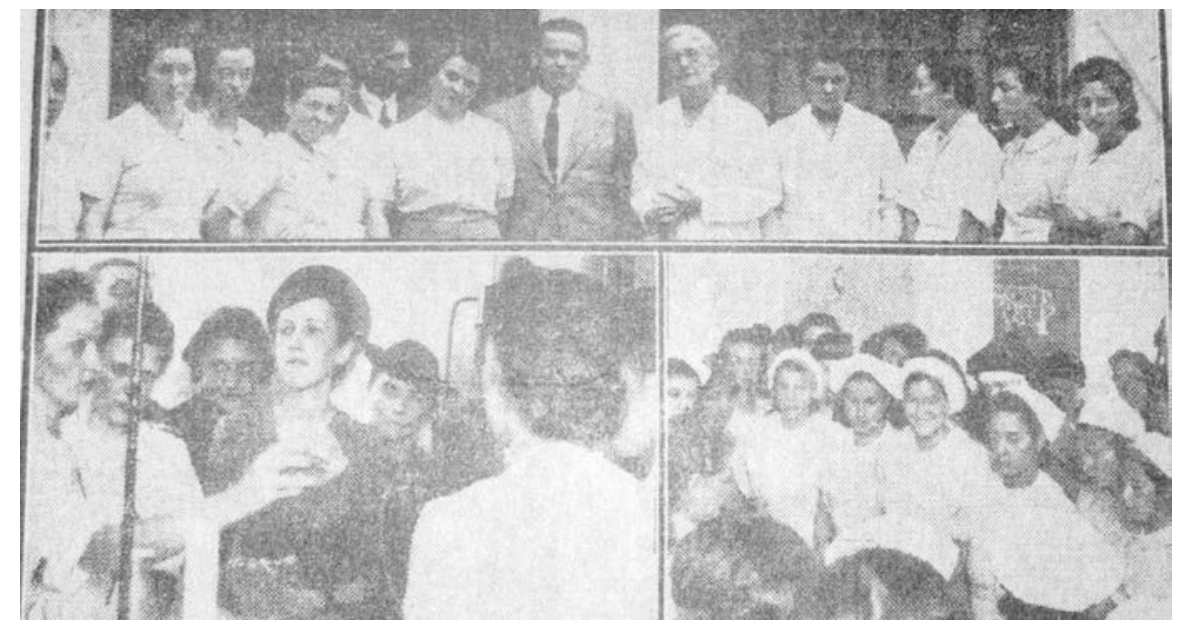

Fonte: Livro de Recortes de Jornais do Acervo do Centro de Memória da Etec Carlos de Campos, em 2012.

Uma reportagem do jornal "O Estado de São Paulo", de $1^{\circ}$ de abril de 1939, encontrada no livro de recortes de jornais do acervo do Centro de Memória da Etec Carlos de Campos, traz o posicionamento desse inspetor sobre o ensino de artes e ofícios da secção feminina das escolas profissionais:

Convencidos todos da desnecessidade de estabelecimento de cursos vocacionais para as futuras donas-de-casa, sujeitar-se-ão estas, doravante, ao aprendizado de todas as disciplinas manuaes do programma, com ensino intensivo de cada uma dellas durante seis mezes para uma habilitação sufficiente. No terceiro anno, entanto, virá a phase de especialização, quer em costuras, quer em chapéus, quer em flores e artes applicadas, phase essa destinada ao exercício da profissão desejada. Como cupola ou linha mestra, sempre figurará a cadeira de dietética, pelo seu alto alcance social e cunho patriótico, sobremaneira dignificante. UMA AULA PRÁTICA DE DIETÉTICA. Às 15 horas, com a presença de todos os directores e professoras convocadas, a professora Celina de Moraes Passos realizou a primeira aula prática de dietética.

Nesse mesmo acervo, um recorte do jornal Diário da Noite, publicado em $1^{\circ}$ de abril de 1939, anunciou a manchete "A alimentação racionalizada como factor decisivo para a melhoria da raça, por meio da formação de perfeitas donas de casa", informando, em segunda chamada, que "a partir do corrente mez passam a ser obrigatórios os cursos 
de dietética nas escolas profissinaes femininas do Estado de São Paulo - Encerrado, com um almoço, o congresso promovido nesta capital”. Nessa matéria jornalística, consta que o referido congresso de diretores e professores de Economia Doméstica da Superintendência do Ensino Profissional se encerrou às $12 \mathrm{~h} 30 \mathrm{com}$ um almoço de 150 talheres, oferecido pelo Instituto Profissional Feminino, e que: "A introducção dos cursos de dietética nas escolas profissionaes de S. Paulo constitue uma innovação, no Brasil”. Ainda nessa reportagem, Francisco Pompêo do Amaral foi entrevistado e elogiou a iniciativa, da qual era ardoroso partidário:

É inútil falar sobre as vantagens indiscutíveis de uma alimentação racionalizada. Todos sabem que a boa alimentação é factor decisivo de saúde, e contribue para a melhoria da raça. E, proporcionando ás moças conhecimentos de dietética, higiene, puericultura, bem como arte e contabilidade doméstica, por meio dos cursos ora introduzidos, as autoridades trabalham para o levantamento do nível moral e material da sociedade. Os cursos formarão moças habilitadas ao desempenho satisfactorio da função que as espera as de donas de casa. E de seus lares, a sua influencia benéfica abrangerá a família, os amigos, a collectividade.

\section{Aula inaugural do curso de auxiliares em alimentação em São Paulo}

O discurso de Francisco Pompêo do Amaral, no documento da aula inaugural dos cursos de dietética (Figura 2), indica que esse médico elaborou os cursos na Superintendência do Ensino Profissional do Estado de São Paulo, nos moldes do médico e professor Pedro Escudero, que, desde 1931, em Buenos Aires, na Argentina, havia começado a dirigir e a estudar a alimentação conveniente nos hospitais e nos refeitórios escolares, tendo iniciado, em 1933, uma grande campanha jornalística em favor da racionalização da alimentação popular, fundando a Escola Municipal de Dietistas, para oferecer pessoal capacitado para tal tarefa (POMPÊO DO AMARAL, 1939 b).

Na gráfica do Instituto D. Escolástica Rosa, Escola Profissional Secundária, em Santos, foram produzidos o documento dessa aula inaugural e o livro didático "Os Cursos de Dietética” (Figura 3), contendo o Decreto Estadual n 10.033, de 3 de março de 1939, que modifica a organização dos cursos de educação doméstica das escolas profissionais 
femininas e cria cursos de dietética para donas de casa e auxiliares em alimentação. O livro citado também traz os programas do curso de educação doméstica e dietética para donas de casa, o discurso da aula inaugural, um quadro com os currículos da organização do Ensino Técnico Profissional Feminino no Estado de São Paulo e, em maior parte, material didático para o ensino nos Cursos de Dietética da Superintendência do Ensino Profissional (POMPÊO DO AMARAL, 1939C). Para Gomes, Selles e Lopes (2013, p.481), os livros didáticos são compreendidos como produções escolares que expressam os sentidos das práticas curriculares, assim como produzem significados sobre as definições do que se ensina, de como se ensina e sobre qual formação docente deve ser desenvolvida.

Figura 2 - Publicação institucional da aula inaugural do curso de Auxiliares em Alimentação, maio de 1939.

Fonte: Centro de Memória da Etec Carlos de Campos, em 2001. 
Figura 3 - Livro institucional da Superintendência do Ensino Profissional

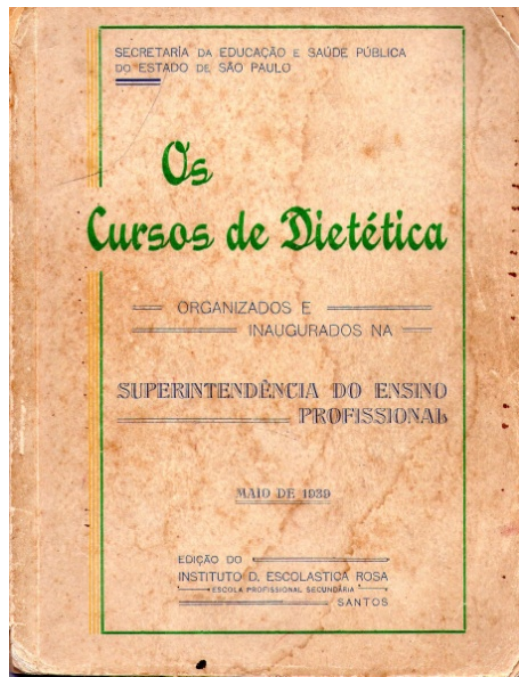

Fonte: POMPEO DO AMARAL, 1939C - Centro de Memória da Etec Carlos de Campos, em 2001.

$\mathrm{Na}$ inauguração dos cursos de "Dietética para Donas de Casa" e "Auxiliares em Alimentação", estiveram presentes autoridades no Instituto Profissional Feminino, da capital, em São Paulo. Durante a sessão solene da instalação dos Cursos de Dietética, compunham a mesa: o interventor federal no estado de São Paulo, sr. Adhemar de Barros; sua esposa, sra. Leonor Mendes de Barros; o secretário da Educação, sr. Alvaro Guião; o professor Carlo Foà, da Universidade de Milão; o dr. Geraldo de Paula Souza; o professor Horácio da Silveira; o major Theophilo Ferraz Filho; o professor dr. Josué de Castro; Raimundo Duprat e o dr. Francisco Pompêo do Amaral. Durante a solenidade de abertura, após o discurso do sr. Álvaro Guião, o professor dr. Josué de Castro, segundo a matéria jornalística do Correio Paulistano de 18 de maio de 1939, fez um discurso de improviso:

[...] O mundo está cheio de sub-nutridos e de gente morrendo a fome; no entanto, há super-producção. Não fosse o desentendimento humano, o mundo teria uma base de equilíbrio, podendo enfrentar todas as suas crises. Conrado Gini elaborou vários inquéritos sobre essa perspectiva da decadência da humanidade com seus maiores pruridos no Occidente. Os casos de super-natalidade que se vêm verificando, proseguiu o orador, é uma prova evidente de decadência. Explicam-se pelas leis biológicas. É o índice de sub-nutrição e não de vitalidade, como se diz no vulgo. É a natureza reagindo contra a sua debilitação na multiplicidade dos nascimentos. A humanidade não quer morrer. Os vários processos de industria, de simplificação, de utilitarismo, de mecanização hodierna em todos os setores da nossa actividade, tiram dos cereais, que são a base 
do alimento, suas vitaminas, como acontece com o trigo. Na Itália, continuou o prof. Josué de Castro, disse que teve occasião de verificar a differença de analyses no trigo da civilização da Europa e o trigo quase selvagem da Abyssinia. Este, vitaminoso cem por cento, aquele numa flagrante inferioridade naquelles princípios vitaes. O Brasil não deve seguir as mesmas diretrizes dos paízes do Velho Continente [...].

Nessa matéria jornalística, consta que o professor dr. Francisco Pompêo do Amaraldeu, a seguir, a sua brilhante aula inaugural, discorrendo longamente sobre dietética, terminando o seu belo discurso com estas palavras:

Com as "auxiliares em alimentação", que deste curso sahirão, a Superintendência do Ensino Profissional poderá aperfeiçoar o ensino nos cursos de vulgarização dos conhecimentos de alimentos que mantem e multiplical-os. Queremos referir-nos aos "Cursos de Dietética para Donas de casa", nos quaes o ensino se exerce de uma forma bem elementar, no sentido de habilitar as alumnas ao convieniente desempenho das attribuições que descorrerem da própria denominação dos mesmos". Com "auxiliares em alimentação", poderemos realizar ainda outros empreeendimentos de alta finalidade educativa, em favor da racionalização alimentar, os quaes exigem pessoal habilitado. E chegaremos, assim, aos poucos, ao Instituto de Nutrição, solenemente promettido ao nosso povo pelo exmo.sr. Secretário da Educação, em opportuna entrevista concedida à imprensa. Tal realização é, sem duvida alguma, indispensável para que se possa abordar, com a necessária amplitude, o problema de tão grande alcance hygienico e social ao qual nos referimos. Num paiz, onde a desnutrição da população é caracter dominante, urge providenciar, quanto antes, que sejam attendidos os direitos physiológicos e vitaes do indivíduo, os quaes condicionam a saúde da collectividade. Auguramos que a inauguração de hoje signifique, antes de mais nada, um passo seguro em favor de outras iniciativas endereçadas ao bem estar público - divisa que póde perfeitamente resumir a acção de todos os bons governos.

O superintendente da Educação Profissional, Horácio da Silveira, encerrou a solenidade de abertura da aula inaugural dos Cursos de Dietética, acompanhando as autoridades na visita às dependências do Instituto Profissional Feminino, assistindo às aulas práticas ministradas pelas professoras Celina de Moraes Passos, Zenith Freire e Zilda Barbella (Figura 1), visitando, inclusive, o Dispensário de Puericultura daquele estabelecimento de ensino.

No Brasil, no mesmo período em que se implantou na Superintendência do Ensino Profissional do Estado de São Paulo o curso de Auxiliares em Alimentação para as moças 
atuarem como auxiliares dos médicos ou em refeitórios e indústrias de alimentação, o presidente Getúlio Vargas, durante a festa de $1^{\circ}$ de Maio, "Dia do Trabalho", que aconteceu no campo de futebol do Vasco da Gama, no Rio de Janeiro, assinou o DecretoLei $n^{\circ}$ 1.238, em 2 de maio de 1939 (ASSOCIAÇÃO, 1991, p.23).O documento dispunha sobre a instalação de refeitórios e a criação de cursos de aperfeiçoamento profissional para trabalhadores. Pode-se afirmar que esse decreto contribuiu para a ampliação do curso de Auxiliares em Alimentação pelo País.

Em 1939, dr. Josué de Castro, a convite do presidente, idealiza o Serviço Central de Alimentação (do qual será nomeado diretor), transformado, em 1941, no Serviço de Alimentação da Previdência Social (Saps) (MELLO e NEVES, 2007; CASTRO, 2003). Segundo o artigo "Idéias sobre Assistência e Educação Alimentares no Brasil", de Umberto Peregrino (Saps, 1950, p.5, citado em ASSOCIAÇÃO, 1991, p.24):

O primeiro restaurante especializado para alimentação de operários, instalou-o, entre nós, o eminente Dr. Paulo Seabra, no Laboratório Orlando Rangel, à rua Ferreira Pontes, $n^{\circ} 148$, pondo-o a funcionar em fevereiro de 1935 [...] apresentado em estudo, intitulado "Cruzados da Alimentação" publicado na Revista Inapiárrios (órgão do IAPI) de janeiro de 1940 e no Boletim do Ministério do Trabalho, Indústria e Comércio de março de 1940. Em decorrência do que, Plínio Cantanhede, então Presidente do IAPI promoveu a construção de um Restaurante destinado aos industriários do Distrito Federal (o prédio da Praça da Bandeira, 96), incumbiu um dos médicos de seu instituto, o Dr. Josué de Castro, de preparar, através de um Curso de Alimentação, o pessoal técnico que devia por a funcionar o Restaurante em Construção. Enquanto isso, funcionava o curso, numa casa à rua Paissandu $n^{\circ} 283$ e o Ministro do Trabalho, Dr. Waldemar Falcão, criava o Serviço de Alimentação da Previdência Social, controlado por um Conselho, sob a Presidência do Professor Alexandre Moscoso. Por divergência com o DASP, resultou a nomeação do Professor Helion Povoa para direção do SAPS.

Geraldo de Paula Souza, presente à aula inaugural em 17 de maio de 1939, foi o idealizador do segundo curso no campo da alimentação no Brasil, ao criar, pelo Decreto Estadual n 10.617, em 24 de outubro de 1939, o Curso de Nutricionistas. Este curso foi implantado no Centro de Estudos sobre Alimentação, um anexo do Instituto de Higiene, por sua vez incorporado, em 1938, à Universidade de São Paulo como instituição complementar e diretamente subordinado à Cadeira de Higiene da Faculdade de 
Medicina. Considerando as palavras de Francisco Pompêo do Amaral na aula inaugural do curso de auxiliares em alimentação, pode-se afirmar que o histórico que consta da obra “Histórico do Nutricionista no Brasil - 1939 a 1989, coletânea de depoimentos e documentos" (ASSOCIAÇÃO, 1991, p.9) precisará ser revisto, por não ser possível considerar que:

O Curso de Nutrição da Faculdade de Saúde Pública, Universidade de São Paulo, é o mais antigo do Brasil. Foi criado em 1939 (Dec. Estadual $\mathrm{n}^{\circ}$ 10.617 de 24/10/39), no então Instituto de Higiene, com o nome de Curso de Nutricionistas, por iniciativa de seu Diretor, Prof. Dr. Geraldo Horácio de Paula Souza. Iniciou seu funcionamento em 1940, oferecendo 20 vagas.

\section{Currículos e protagonistas nos primeiros cursos no campo da alimentação e nutrição no Brasil}

Os currículos dos primeiros cursos no campo da alimentação e nutrição no Brasil estão apresentados no quadro 1, enquanto que, no quadro 2, estão os nomes dos docentes que, em diferentes períodos, participaram desses cursos. Comparando os diversos currículos, observa-se que eram projetados para a formação de técnicas em alimentação com diferentes perfis. O curso criado por Francisco Pompêo do Amaral focou na alimentação do indivíduo - da criança à fase adulta -, promovendo a educação alimentar dos adolescentes a partir dos refeitórios escolares e dos estudos nutricionais realizados pela equipe médica da Superintendência do Ensino Profissional no Estado de São Paulo. 
Quadro 1 - Currículos dos primeiros cursos no campo da alimentação e nutrição no Brasil

\begin{tabular}{|c|c|c|}
\hline $\begin{array}{l}\text { Curso de Auxiliares em } \\
\text { Alimentação, } 1939 \text { (POMPÊO DO } \\
\text { AMARAL, 1939C) }\end{array}$ & $\begin{array}{l}\text { Curso de Nutricionistas - Instituto } \\
\text { de Higiene, } 1940 \text { a } 1945 \\
\text { (ASSOCIAÇÃO 1991, p. 13) }\end{array}$ & $\begin{array}{l}\text { Curso de Auxiliares de } \\
\text { Alimentaçãa - IAPI } 1940 \\
\text { (ASSOCIAÇÃO, 1991, p. 27) }\end{array}$ \\
\hline $\begin{array}{l}\mathbf{1}^{\circ} \text { ano } \\
\text { Dietética } \\
\text { Puericultura } \\
\text { Arte culinária } \\
\text { Artes domésticas } \\
\text { Contabilidade doméstica } \\
\text { Noções de química e higiene } \\
\text { Práticas: Cozinha, Laboratório, } \\
\text { Dispensário de Puericultura. } \\
\mathbf{2}^{\circ} \text { ano } \\
\text { Dietética } \\
\text { Puericultura } \\
\text { Higiene } \\
\text { Contabilidade doméstica } \\
\text { Práticas: Cozinha, Refeitórios, } \\
\text { Laboratórios. Colônia climática } \\
\text { permanente-Santos. Dispensários } \\
\text { de Puericultura. Hospitais } \\
\text { infantis. }\end{array}$ & $\begin{array}{l}1 \text { ano } \\
1^{\circ} \text { período (01 fev. a } 15 \text { abr.) } \\
\text { Anatomia e fisiologia aplicada; } \\
\text { Bioquímica; } \\
\text { Dietética e arte culinária. } \\
2^{\circ} \text { período ( } 16 \text { abr. a } 30 \text { jun.) } \\
\text { Nutrição normal; } \\
\text { Bromatologia; } \\
\text { Dietética e arte culinária. } \\
3^{\circ} \text { período ( } 16 \text { jul. a } 30 \text { set.) } \\
\text { Nutrição normal; } \\
\text { Alimentação da gestante e da } \\
\text { criança; } \\
\text { Dietética e arte culinária; } \\
\text { Alimentação e saúde pública. } \\
4 \text { período (01 out. a 15 dez.) } \\
\text { Dietética e arte culinária; } \\
\text { Noções de patologia da nutrição; } \\
\text { Alimentação e Saúde Pública } \\
\text { Práticas ou estágios: laboratórios, } \\
\text { centros de saúde, hospitais, } \\
\text { escolas, fábricas, restaurantes ou } \\
\text { outros locais, sempre que } \\
\text { necessário. }\end{array}$ & $\begin{array}{l}\text { 1 semestre (6 meses) } \\
\text { Biologia Geral; } \\
\text { Noções de Química e } \\
\text { Laboratório; } \\
\text { Alimentação e Nutrição; } \\
\text { Dietética; } \\
\text { Arte Culinária e Cozinha } \\
\text { Dietética; Alimentar e } \\
\text { Economia Alimentação } \\
\text { Organização de Alim. } \\
\text { Coletiva. }\end{array}$ \\
\hline
\end{tabular}

Quadro 2 - Docentes dos primeiros cursos no campo da alimentação e nutrição no Brasil, entre 1939 e 1948

\begin{tabular}{|c|c|c|}
\hline $\begin{array}{l}\text { Curso de Auxiliares em } \\
\text { Alimentação- SEP - } \\
\text { 1939 a 1948 }\end{array}$ & $\begin{array}{l}\text { Curso de Nutricionistas - } \\
\text { Instituto de Higiene, } 1940 \text { a } 1945 \\
\text { (ASSOCIACÃO, 1991, p. 13) }\end{array}$ & $\begin{array}{l}\text { Curso de Auxiliares } \\
\text { Alimentação - IAPI 1940 } \\
\text { (ASSOCIAÇÃO, 1991, p. 27) }\end{array}$ \\
\hline $\begin{array}{l}\text { Docentes: } \\
\text { Dr. Francisco Pompêo do Amaral } \\
\text { Celina de Moraes Passos } \\
\text { Zenith Freire } \\
\text { Zilda Barbella } \\
\text { Julieta Viccari } \\
\text { Yonne Cintra de Souza } \\
\text { Carmen Bonvicini } \\
\text { Odilla Ferraz } \\
\text { Isabel Marcondes Machado } \\
\text { HonorinaNaclerioHomen Rossio } \\
\text { Maria José Barbosa Carvalho } \\
\text { Dr. Jorge de Moraes Barros Filho } \\
\text { Iris de Krauss } \\
\text { Dr. Mario Taddeo }\end{array}$ & $\begin{array}{l}\text { Docentes: } \\
\text { Dr. Alexandre Wancolle; } \\
\text { Dr. Antonio de Barros de Ulhôa } \\
\quad \text { Cintra; } \\
\text { Dr. Geraldo Horácio de Paula } \\
\quad \text { Souza; } \\
\text { Dr. Francisco Antônio Cardoso; } \\
\text { Margarida Rosa Passos Ferber; } \\
\text { Dr. Pedro Alcantara Marcondes } \\
\quad \text { Machado; } \\
\text { Dr. Joaquim Leme da Fonseca; } \\
\text { Lucia Jardim; } \\
\text { Dina Salvatori; } \\
\text { Maria Rosa S. Pinheiro; } \\
\text { Dr. Oswaldo Augusto }\end{array}$ & $\begin{array}{l}\text { Docentes: } \\
\text { Adhemar Hooper Pinto; } \\
\text { Celina de Moraes Passos; } \\
\text { Cleto Seabra Veloso; } \\
\text { Dante Nascimento Costa; } \\
\text { Hélio Luz; } \\
\text { Pedro Alves da Costa Couto; } \\
\text { Rubem de Siqueira; } \\
\text { Rubens Descartes de Paula; } \\
\text { Thalino Botelho; } \\
\text { Thomaz de Figueiredo Mendes. }\end{array}$ \\
\hline
\end{tabular}


Dr. Jose G. Simões

Irene Durelli

Ruth Corrêa de Lima

Maria de Lourdes Almeida Tedechi

Rosaria Macaluso

Maria de Lourdes Cambraia Salles

Judith de Barros Lima

Também envolveu as alunas em inquéritos socioeconômicos, com a finalidade de formar profissionais para a coletividade, contribuindo para sua atuação em refeitórios e hospitais.

No entanto, o curso criado por Geraldo de Paula Souza (Figura 4) focou na alimentação e saúde pública, ressaltando estudos de anatomia e fisiologia, priorizando os aspectos biológicos. Quanto ao curso criado pelo dr. Josué de Castro, pelo curto período de formação de seis meses, focou especialmente na formação de profissionais para atuarem nos refeitórios junto aos trabalhadores. O segundo curso oferecido pelo Saps, em 1944, sofreu alteração curricular, passando a dois anos de duração, e com nova denominação: "Curso de Nutricionistas" (ASSOCIAÇÃO, 1991, p.31). A professora Celina de Moraes Passos se afastou da educação profissional em São Paulo e ministrou aulas nesses dois cursos oferecidos pelo Saps no Rio de Janeiro.

Figura 4 - Formandas com Geraldo de Paula Souza, na Escola de Higiene e Saúde Pública, primeira turma, em 1940

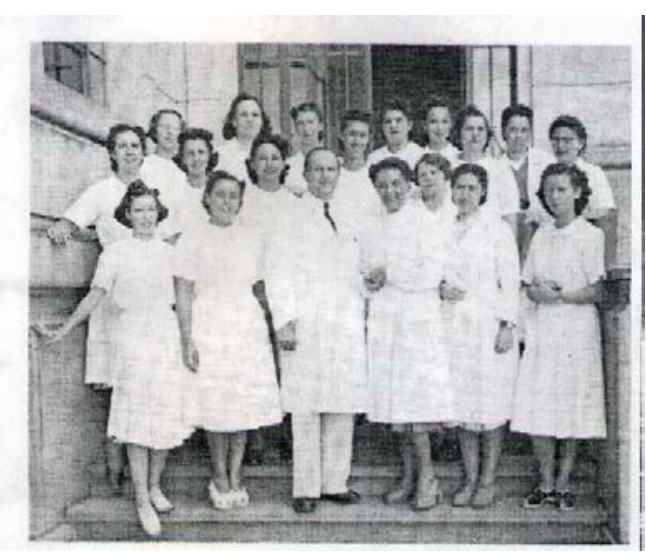

Fonte: Centro de Memória da Faculdade de Saúde Pública, em 2010. 


\section{Práticas escolares e pedagógicas no ensino profissional em São Paulo}

As obras de Francisco Pompêo do Amaral mostram como é possível, a partir das práticas pedagógicas e escolares e com apoio institucional, fornecer elementos para a pesquisa no campo da alimentação e nutrição. Como médico-chefe do setor de Serviços Médicos e responsável pela seção de Alimentação e Higiene Escolar na Superintendência do Ensino Profissional do Estado de São Paulo, composta de três subseções, em duas delas este médico participou diretamente das de "Alimentação e Nutrição" e "Pesquisas e Ensino da Alimentação", nas quais atuou com a sua equipe de dietistas, realizando atividades de pesquisas e de magistério no Instituto Profissional Feminino, na capital (LAURINDO, 1962, v.1, p.216).

Para diferenciar as práticas escolares das pedagógicas, em diferentes épocas, e citadas neste artigo, adotaram-se os conceitos estabelecidos por Gvirtz (2005, p. 25), que considera as práticas discursivas escolares como produções da escola e as práticas discursivas pedagógicas, produções sobre a escola. Esta diferenciação é importante para entender o cotidiano da escola, o trabalho realizado por professores e estudantes em sala de aula, e o proposto pelos administradores, geralmente oriundos de regulamentação dos gestores da educação profissional pelo Estado.

No mesmo ano em que criou o primeiro curso no campo da alimentação no Brasil, em 1939, Pompêo do Amaral publicou o livro "Comer para viver... Alimentos - Princípios Imediatos - Sais Minerais". Nessa obra, discute os alimentos, com os princípios imediatos a se conhecer ao comer para viver, apresentando receitas de produtos à base de milho, incluindo diversos tipos de pães, finalizando com a influência do solo sobre o teor de sais minerais nos alimentos.

Quando o governo do presidente Getúlio Vargas completou dez anos, uma "Feira de Amostras", com a participação de todos os estados da Federação aconteceu em dezembro de 1939, no Rio de Janeiro. Na matéria jornalística “A surpreendente exibição do Ensino Profissional Paulista na Feira de Amostras do Rio de Janeiro", consta que, no pavilhão do Estado de São Paulo, a Superintendência do Ensino Profissional ocupou um 
espaço de 200 metros quadrados. Embora pequeno, impressionou o presidente Getúlio Vargas e seus ministros. Para esse evento, foram elaboradas diversas publicações na Superintendência. Relativamente à alimentação e nutrição. Foram divulgadas as seguintes publicações: "Os cursos de Dietética” ( $3^{\text {a }}$ edição) e "Comer para Viver" (Figura 5), de Francisco Pompêo do Amaral; "Princípios gerais de alimentação”, de Zenith Freire Ferreira, e "Organização simples e prática de Cardápios Racionais para Internatos Colegiais", de Celina de Moraes Passos (LAURINDO, 1962, v.2, p.140-1).

Com a manchete “O pavilhão de São Paulo na Feira de Amostras do Rio”, o jornal a Folha da Manhã, de 2 de dezembro de 1939, registra que à superintendência coube o encargo de fazer uma demonstração dos métodos de ensino profissional adotados em São Paulo, informando que os Cursos de Dietética e os Dispensários de Puericultura do Instituto Profissional Feminino, e a Escola Profissional Agrícola de Pinhal, apresentaram gráficos, quadros murais e fotografias demonstrativas dos trabalhos realizados no campo da assistência à infância e da educação doméstica da mulher (FREITAS, 1954, p.115).

Figura 5 - Livro institucional "Comer para Viver" da Superintendência do Ensino Profissional do Estado de São Paulo, de 1939

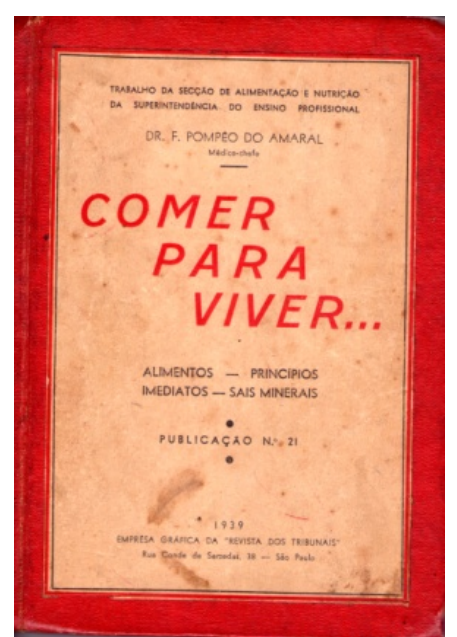

Fonte: Acervo pessoal de Debble Smaíra Pasotti, em 2012.

Em 1940, Pompêo Amaral participou da “Jornada sobre Alimentação”, promovida pelo Instituto de Organização do Racional do Trabalho (Idort), na Semana da Alimentação, colaborando com a sua organização. Segundo Tenca: 
A presença do Idort, a partir dos anos 30, foi marcante: na reorganização do ensino profissional no Brasil; na estruturação do Departamento de Administração do Serviço Público (Dasp); na criação do Sesi e do Sesc; na Reorganização Administrativa do Governo do Estado (Rage), em São Paulo; em iniciativas vinculadas direta ou indiretamente à Fiesp, como na criação da Escola Livre de Sociologia e Política, em 1933, antecipando-se mesmo à constituição da Universidade de São Paulo, criada em 1934, no governo Armando de Salles Oliveira, que foi um dos fundadores e o primeiro presidente do Idort em 1931. Esses fatos indicam a interferência direta dos representantes da indústria paulista na implementação de políticas sociais, de um lado, e, de outro, o investimento na reestruturação da burocracia, tanto no setor privado como em instituições governamentais (TENCA, 2006, p. 41).

Entre os livros que escreveu está “Alimentação - Conferências", que inclui diversas das que o médico proferiu nessa “Jornada sobre Alimentação”. Dentre elas, uma sobre “Consequências da má Alimentação do Operário”, na Escola de Comércio “Álvares Penteado", em 24 de setembro de 1940, apresentando um panorama da situação social e econômica do País, ressaltando a importância da alimentação para o indivíduo e a coletividade (POMPÊO DO AMARAL, 1941a, p. 13-9):

[...] Olhem para os gráficos que trouxe para este recinto e terão ideia exata da escassa duração de vida, da reduzida resistência física e da precariedade das condições de saúde da nossa gente. [...] - Mas que tem tudo isso com alimentação? - hão de querer perguntar-me. A alimentação constitue o alicerce sobre o qual repousa o valor físico do indivíduo e da coletividade. Dados como os que se assinalam, entre nós, denunciam constantemente carência alimentar. Fossem as rações suficientes em quantidade e qualidade e seguramente estes não se verificariam. As altas cifras de morbilidade e mortalidade acusam diminuição da resistência orgânica e infecções, maior suscetibilidade do organismo às agressões de agentes patológicos. Essa predisposição à aquisição de doenças verifica-se sempre que o organismo está insuficiente ou inconvenientemente nutrido. [...]

Além desta, pronunciou, nessa mesma jornada, em 28 de setembro de 1940, na Faculdade de Direito da Universidade de São Paulo, a conferência "A alimentação do intelectual". Ainda na mesma data, 20 operários participaram de almoço, oferecido por Horácio Augusto da Silveira, da Superintendência do Ensino Profissional do Estado de São Paulo, e pelo jornal Diário da Noite, no Instituto Profissional Feminino da capital. Esses operários trabalhavam nas empresas "A Sul América”, de doces e conservas, "André 
Nunes e Filhos", de calçados, e no "Laboratório Kolkin". Estiveram presentes, no almoço, Francisco Pompêo do Amaral e os médicos Geraldo de Paula Souza e Mario Egydio de Souza Aranha, do Instituto de Higiene de São Paulo. O jornalista Nelson Candido Motta representou os diretores do Diário da Noite, Assis Chateaubriand e Carlos Rizzini.

Os convidados foram recebidos com uma atividade recreativa organizada pela diretora do instituto, Laia Pereira Bueno, realizada por 105 alunas, sob a regência do maestro Miguel Izzo, apresentando-se durante o almoço. Um cardápio foi impresso e entregue aos 20 operários e aos convidados (médicos, jornalistas), na presença do Secretário da Educação e Saúde Pública, Mario Lins, participantes do almoço oferecido por Horácio Augusto da Silveira e Laia Pereira Bueno, no sábado de 28 de setembro de 1940, às 11 horas, no Instituto Profissional Feminino, no Brás, sempre na capital.

Francisco Pompêo do Amaral, quando pronunciou o seu discurso "A ação da Superintendência do Ensino Profissional de São Paulo a favor da racionalização da alimentação", em 17 de outubro de 1940, para homenagear a primeira turma de formadas no curso de "Auxiliares em Alimentação", deixou registrada a colaboração do Instituto de Higiene e qual deveria ser a principal função dessas profissionais formadas no Instituto Profissional Feminino ao dizer: “Enfim, está já bem dado o primeiro passo para a realização prática de uma campanha em favor da melhor alimentação do nosso povo [...]” (POMPÊO DO AMARAL, 1941a, p.98). As alunas formadas na primeira turma do curso de “Auxiliares em Alimentação” eram, em sua maioria, professoras do curso de Educação Doméstica, de escolas profissionais da Superintendência do Ensino Profissional no Estado de São Paulo, conforme indica matéria jornalística no "Diário da Noite", de 28 de setembro de 1940, encontrada no livro de recortes de jornais do acervo do Centro de Memória da Etec Carlos de Campos, com a manchete "As atividades do curso em Auxiliares em Alimentação da Superintendência do Ensino Profissional”, relacionando os nomes:

Ana Nunes (professora substituta de Higiene no IPF); Eloiza Cesar Campos (mestre ajudante da Escola Profissional Feminina de Sorocaba); Elza Pinto; Elvira de Felício; Eunice da Costa (professora de Dietética e Química alimentar da Escola Profissional Feminina de Sorocaba); Eunice Zuhlke (dietista do Laboratório da Escola Profissional Feminina de Mococa), Irene Durelli (professora substituta de Dietética do IPF); Julieta 
Vicari (professora de Dietética do Instituto Escolástica Rosa, em Santos); Maria Cecília Faria Guimarães (dietista da Gota de Leite, em Santos); Nelly França; Nice Mauro; Noemia da Silveira (professora de Dietética do Instituto Escolástica Rosa, em Santos); NoemiaBiason (professora de Dietética da Escola Profissional Feminina de São Carlos); Odette Monteiro Prado (professora substituta de Arte Culinária no IPF); Olga Pavesi (professora de Dietética da Escola Profissional Bento Quirino, em Campinas); Rachel Aurichio e Tosca Rossi (professora de Dietética da Escola Profissional de Santo André).

Na solenidade de formatura da primeira turma de "Auxiliares em Alimentação" e de "Dietética para Donas de Casa" no Instituto Profissional Feminino, o jornal "Folha da Noite", de 17 de outubro de 1940, publicou que a abertura do evento aconteceu com o orfeão da escola, regido pelo maestro Miguel Izzo, cantando o Hino Nacional. Estiveram presentes no evento a primeira dama do governo do estado de São Paulo, Leonor Mendes de Barros, paraninfa dessas turmas, o secretário da Educação e Saúde Pública, Mario Lins, e o professor Geraldo de Paula Souza, diretor do Instituto de Higiene da Universidade de São Paulo, recebidos pelo superintendente do Ensino Profissional, Horácio Augusto da Silveira, a diretora Laia Pereira Bueno e o vice-diretor, Benedito Tolosa, do Instituto Profissional Feminino, da capital, no Brás, em São Paulo.

Quanto aos cursos de "Dietética para Donas de Casa”, esses foram ministrados nas escolas profissionais que ofereciam os cursos vocacionais de "Educação Doméstica". Francisco Pompêo do Amaral, em 23 de novembro de 1940, ministrou a conferência "A desnutrição entre os escolares", na Diretoria do Serviço de Saúde Escolar do Departamento da Educação, propondo a criação de refeitórios escolares. No texto dessa conferência, é possível identificar que esse médico, à época, considerava tanto as profissionais formadas no curso de "Auxiliares em Alimentação" quanto no curso de “Nutricionistas", parceiras entre si e auxiliares dos médicos (POMPÊO DO AMARAL, 1941a, p. 132)

Pompêo do Amaral apresentou, no I Congresso Nacional de Saúde Escolar, realizado em São Paulo entre 21 e 27 de abril de 1941, três trabalhos referentes às pesquisas que desenvolvia sobre as práticas pedagógicas e escolares na instituição: “ $A$ Educação Alimentar promovida pela Superintendência do Ensino Profissional”; “O 
Refeitório Modelo do Instituto Profissional Feminino" e "A alimentação nos refeitórios dos internatos mantidos nos estabelecimentos subordinados à Superintendência do Ensino Profissional".

Em seu acervo pessoal, que se encontra com a família, localizamos seis artigos publicados na Revista Agrícola Brasileira entre 1941 e 1942. No primeiro ("O fubá integral e a alimentação do povo brasileiro"), de outubro de 1941, anteriormente divulgado na Folha da Manhã, ressaltava a importância da substituição do trigo pelo milho na produção de pães e de outros produtos na mesa do trabalhador brasileiro. Nesse artigo, cita a sua obra "Comer para viver...", na qual reuniu 47 receitas de preparações com milho (POMPÊO DO AMARAL, 1939a).

Em 14 de junho de 1941, o médico foi comissionado na Secretaria da Agricultura, passando a atuar como membro da Comissão de Alimentação Pública, então constituída pelo governo do estado. Durante o período em que esteve na Secretaria, foi substituído na Superintendência do Ensino Profissional pelo médico e professor de higiene dr. Emiliano Nóbrega, da Escola Profissional Agrícola Industrial de Pinhal. No ano seguinte, Horácio Augusto da Silveira também foi comissionado na Secretaria da Agricultura, para, segundo Leitão (1961, p.24), "prestar serviços na organização das Escolas Práticas de Agricultura planejadas pelo governo Fernando Costa".

Nessa comissão, permaneceu até 22 de abril de 1942, vindo a se desligar assim que percebeu que não pretendiam executar a praxe necessária para a comercialização, higienização e fiscalização de leite e derivados. Enquanto esteve na secretaria, fez várias publicações, divulgadas na Exposição de Alimentação, em novembro de 1941, a primeira, segundo o médico, a se realizada no Brasil (POMPÊO DO AMARAL, 1945).

Em 1945, Pompêo do Amaral publicou o livro "Política Alimentar", pela Editora Brasiliense, em São Paulo, incluindo práticas escolares e pedagógicas realizadas em inquéritos com as famílias de 800 meninas do Instituto Profissional Feminino. No prefácio do livro, do sociólogo Caio Prado Junior, é possível identificar o sujeito social que foi Francisco Pompêo do Amaral como médico, professor, cientista e político no campo da alimentação e nutrição: 
O Sr. Pompêo do Amaral vai ao fundo do problema. Embora situando-se no terreno de sua especialidade, nele não se encerra. $E$ por isso não procura soluções unicamente no setor restrito e próprio da questão alimentar. Suas vistas abrangem o conjunto do problema, e ele reconhece que a matéria da sua especialidade representa apenas um de seus aspectos. É nisto, sem dúvida, que reside a grande e principal mérito da contribuição que traz. Quando um técnico sabe colocar-se num ponto de vista amplo, e sua visão ultrapassa o setor da especialidade de que se ocupa, para situar-se no largo campo do conhecimento geral, ele une a técnica ao espírito filosófico, e realiza com isto a verdadeira obra científica.

\section{Referências}

ASSOCIAÇÃO BRASILEIRA DE NUTRIÇÃO. Histórico do nutricionista no Brasil. 1939 a 1989. Coletânea de depoimentos e documentos. São Paulo: Atheneu Editora São Paulo, 1991.

CASTRO, Anna Maria de. (Org). Josué de Castro: semeador de idéias. Instituto Técnico de Capacitação e Pesquisa da Reforma Agrária - ITERRA e Instituto Josué de Castro, 1. ed., São Paulo: Gráfica e Editora Peres Ltda., 2003.

FREITAS, Zoraide Rocha de. História do ensino profissional no Brasil. São Paulo. Associação dos Servidores do Ensino Profissional, 1954.

GOMES, Maria Margarida; SELLES, Sandra Escovedo; LOPES, Alice Casimiro. Currículo de Ciências: estabilidade e mudança em livros didáticos. Educação e Pesquisa. São Paulo, v. 39, n. 2, p. 477-492. abr./jun., 2013.

GVIRTZ, Silvina. Do currículo prescrito ao currículo de classe: um olhar sobre os cadernos de classe. Bragança Paulista: Editora Universitária São Francisco, 2005.

JULIA, Dominique. A cultura escolar como objeto histórico. Revista Brasileira de História da Educação, n. 1, p. 10, 2001.

LAURINDO, Arnaldo. 50 anos de educação profissional: Estado de São Paulo1911 a 1961. $1^{\text {a }}$ Ed. São Paulo: Editora Gráfica Irmãos Andrioli S.A., 1962.

LEITÃO, Arnaldo. Horácio Augusto da Silveira. Revista do Professor, out. /dez. 1961. 
MASSUCATO, José Geraldo; BARBANTI, Valdir José. Histórico da Escola de Educação Física e Esporte da Universidade de São Paulo. Revista Paulista de Educação Física, São Paulo, v. 13, p. 7-12. dez., 1999.

MELO, Marcelo Mário de; NEVES, Teresa Cristina Wanderley (Org.). Josué de Castro. Perfis parlamentares 52. Brasília: Câmara dos Deputados, Coordenação de Publicações, 2007.

MORAES, Carmen Sylvia Vidigal; ALVES, Julia Falivene (Org). Álbum Fotográfico: - uma história em imagens - escolas profissionais públicas do Estado de São Paulo. Centro Paula Souza. 1. ed. São Paulo: Imprensa Oficial, 2002.

MORAES, Carmen Sylvia Vidigal; ZAIA, Iomar Barbosa; VENDRAMETO, Maria Cristina. Arquivos escolares e pesquisa histórica: fontes para o estudo da educação brasileira. ProPosições, v. 16, n. 1 (46), jan./abr. p. 117-133. 2005.

PASSOS, Celina de Moraes. Noções sobre química alimentar. São Paulo: Companhia Editora Nacional, 1938.

POMPÊO DO AMARAL, Francisco Pompêo do. Trabalhos e títulos do Doutor Francisco Pompêo do Amaral, para concorrer a membro correspondente nacional, de 4 de agosto de 1963. Acervo do Arquivo da Academia Nacional de Medicina. Rio de Janeiro, 16/05/2011.

POMPÊO DO AMARAL, Francisco Pompêo do. A Política Alimentar. São Paulo, Editora Brasiliense Limitada, 1945.

POMPÊO DO AMARAL, Francisco Pompêo do. O fubá integral e a alimentação do povo brasileiro. Revista Agrícola Brasileira, São Paulo, out. 1941b.

POMPÊO DO AMARAL, Francisco Pompêo do. Alimentação - conferências. Local: Escola Profissional Secundária, 1941a. Trabalho da Secção de Alimentação e Nutrição da Superintendência do Ensino Profissional. Publicação $n^{\circ}$ 25, Composto e impresso no Curso de Artes Gráficas do Instituto D. Escolástica Rosa.

POMPÊO DO AMARAL, Francisco Pompêo do. Comer para viver. Alimentos: princípios imediato, - sais minerais. 1. ed. São Paulo: Empresa Gráfica da "Revista dos Tribunais", 1939a. Trabalho da Secção de Alimentação e Nutrição da Superintendência do Ensino Profissional.

POMPÊO DO AMARAL, Francisco Pompêo do. Os Cursos de dietética. 1. ed. Santos: Edição do Instituto D. Escolástica Rosa. Escola Profissional Secundária, maio1939c. Organizados e Inaugurados na Superintendência do Ensino Profissional. 
POMPÊO DO AMARAL, Francisco Pompêo do. Aula inaugural. Santos: Edição do Instituto D. Escolástica Rosa, 1939b.

SOUZA, Rosa Fátima. Preservação do patrimônio escolar no Brasil: notas para um debate. Revista Linhas. Florianópolis, v. 14, n. 26, p. 199-221, jan./jun. 2013. Disponível em: <http://www.periodicos.udesc.br/index.php/linhas/article/viewFile/1984723814262013199/ 2539> Acesso em: 25 jul. 2013.

TENCA, Álvaro. Senhores dos trilhos: racionalização, trabalho e tempo livre nas narrativas de ex-alunos do Curso de Ferroviários da Antiga Paulista. São Paulo: Editora UNESP, 2006. $332 \mathrm{p}$.

UNIVERSIDADE DE SÃO PAULO. Faculdade de Saúde Pública. Serviço de Graduação. Histórico escolar de nutricionista de Celina de Moraes Passos. São Paulo, 2/07/2012.

VIÑAO FRAGO, Antonio. Relatos e relações autobigráficas de professores e mestres. In: MENEZES, M. C. (Org.) Educação, memória, história: possibilidades, leituras. Campinas: Mercado de Letras, 2004. p. 333-373.

VIÑAO FRAGO, Antonio. Memória, patrimônio y educación. Revista História da Educação, v. 15, n. 33, jan./abr. p. 31-62. 2011. Disponível em: <http://secr.ufrgs.br/asphe/article/view/20100/11674>. Acesso em: 16 abr. 2012. 
Recebido em: 17/03/2014 Aprovado em: 30/05/2014

Universidade do Estado de Santa Catarina - UDESC Programa de Pós-Graduação em Educação - PPGE

Revista Linhas

Volume 15 - Número 28 - Ano 2014 revistalinhas@gmail.com 